\title{
Cardiac Involvement of Rosai-Dorfman Disease Causing an Aesthetic Problem in a Young Woman
}

\author{
Remzi Tınazl11 ${ }^{1}$ Pınar Tunçbilek Özmanevra², Eda Tuna Yalçınozan1, Ferhat Erişir1 \\ ${ }^{1}$ Department of Otorhinolaryngology-head and Neck Surgery, Near East University School of Medicine, Nicosia, Cyprus \\ ${ }^{2}$ Department of Otorhinolaryngology-head and Neck Surgery, Kyrenia University School of Medicine, Kyrenia, Cyprus
}

A 32-year-old woman was referred to our ENT clinics for the evaluation of multiple symmetrical swellings in her neck. In the patient's family history, there was cross-cousin marriage between her grandparents. The patient and her sister had severe hearing loss and type 1 diabetes mellitus since their childhood. The patient also had symmetric hyperpigmented and erythema nodosum-like lesions on the anterior surface of the lower extremities which would suggest that she has an immune system disorder (Figure 1a). The head and neck examination revealed bilateral symmetrical firm, painless, and fairly mobile periparotid and submandibulary masses (Figure 1b). Magnetic resonance imaging (MRI) scans on the neck revealed conglomerated lymph nodes of a size $45 \times 27 \mathrm{~mm}$ on the right parotid region and $37 \times 22 \mathrm{~mm}$ on the left and also a solid lymph node of a size $26 \times 18 \mathrm{~mm}$ on the right submandibular region and $21 \times 18$ on the left. According to the patient's blood sample tests, C-reactive protein and rythrocyte sedimentation rate were high, while capillary protein electrophoresis showed polyclonal hypergammaglobulinemia. Antithyroglobulin, anti-thyroid peroxidase, and anti-nuclear antigen were also positive. The patient's cardiac MRI showed that there was a uniform contoured mass lesion which is adherent to the

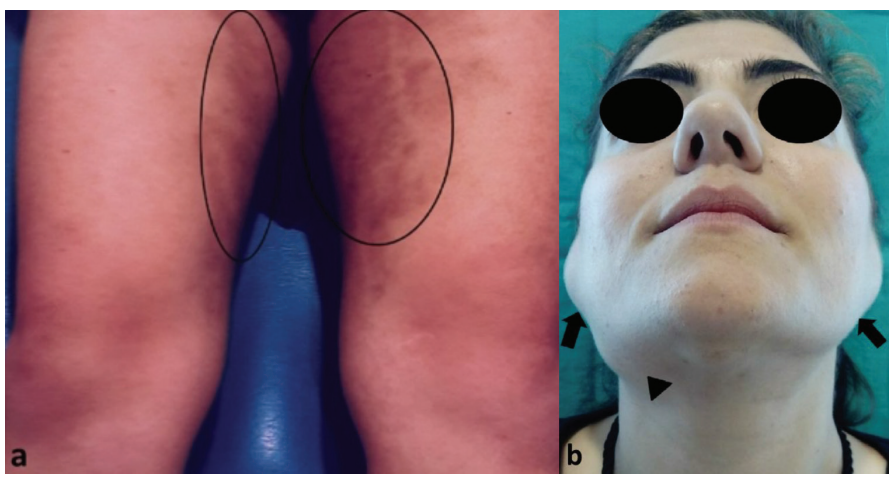

FIG. 1. a, b. Photos of the patient. (a) The colored skin lesions on her lower extremities. (b) The preoperative view of the patient with the right submandibular (black arrow head) and bilateral parotid region masses (black arrows). interventricular septum with a protrusion through the right ventricular lumen, having the size of $10 \times 15 \mathrm{~mm}$. Compared with the myocardium, it had a hyperintense appearance in the T2-weighted series and a homogenously enhancing mass lesion after IV contrast material injection (Figure 2). Besides, similar mass lesions were observed in the anterior mediastinum. The masses on the neck did not cause any problems other than cosmetic appearance, so excisional biopsy from the parotid and submandibular regions was performed for diagnosis and cosmetic reconstruction. The histopathological evaluation showed that the normal layout of the lymph node was impaired due to the marked enlargement of the lymph sinuses and there are also numerous lymphocytes, plasma cells, and large vesicular nuclei histiocytes within. Most of these histiocytes have intact lymphocytes

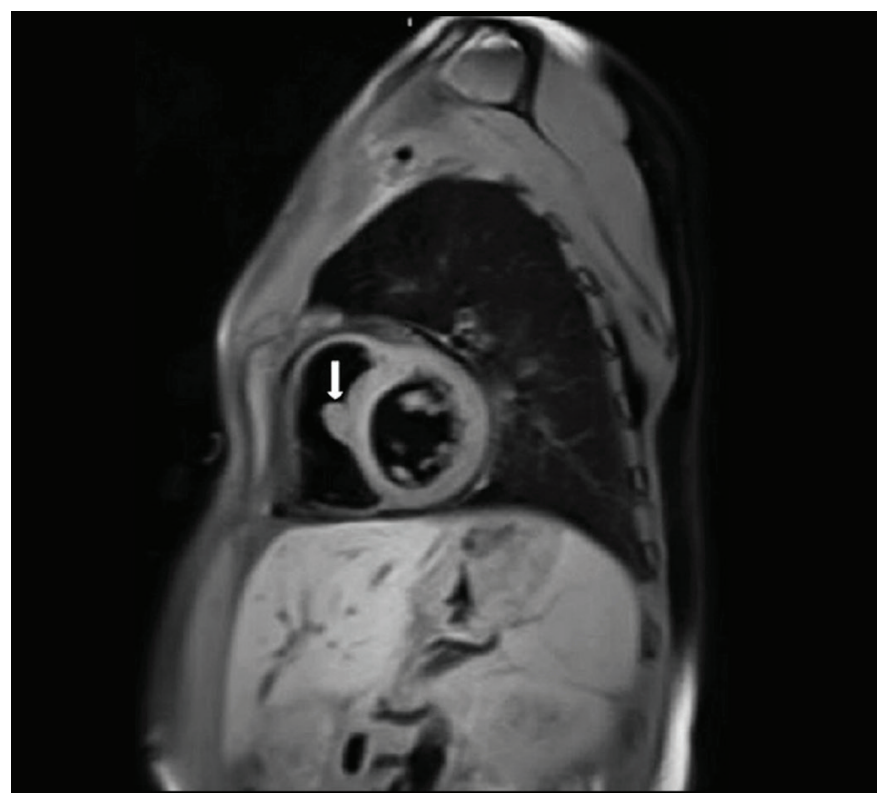

FIG. 2. Histophatologic features of the biposy material. Sagittal section with $\mathrm{T} 2$ sequences of cardiac magnetic resonance imaging scan indicates a $10 \times 15 \mathrm{~mm}$ mass in the cardiac interventricular septum (white arrow).

\footnotetext{
Address for Correspondence: Eda Tuna Yalçınozan, Department of Otorhinolaryngology-head and Neck Surgery, Near East University, School of Medicine, Nicosia, Cyprus Phone: +90 $5338592618 \quad$ e-mail: dr.etuna@gmail.com ORCID: orcid.org/0000-0001-5392-5937

Received: 03 December 2019 Accepted: 02 March 2020 • DOI: 10.4274/balkanmedj.galenos.2020.2019.12.14

Available at www.balkanmedicaljournal.org

Cite this article as:

Tınazlı R, Tunçbilek Özmanevra P, Tuna Yalçınozan E, Erişir F. Cardiac involvement of Rosaidorfman Disease: Causing Aesthetic Problem in a Young Woman Balkan Med J 2020;37:222-3

${ }^{\circ}$ Copyright 2020 by Trakya University Faculty of Medicine / The Balkan Medical Journal published by Galenos Publishing House
} 
and plasma cells in their cytoplasm, which is significant for the diagnosis of Rosai-Dorfman disease (RDD), which are referred to as "emperipolesis" or "lymphocytophagocytosis" (Figures 3a and $3 b$ ). During the 24-month follow-up period, the size of the mediastinal and intracardiac masses did not change and the skin lesions were not activated. For this report, an informed written consent was obtained from the patient.
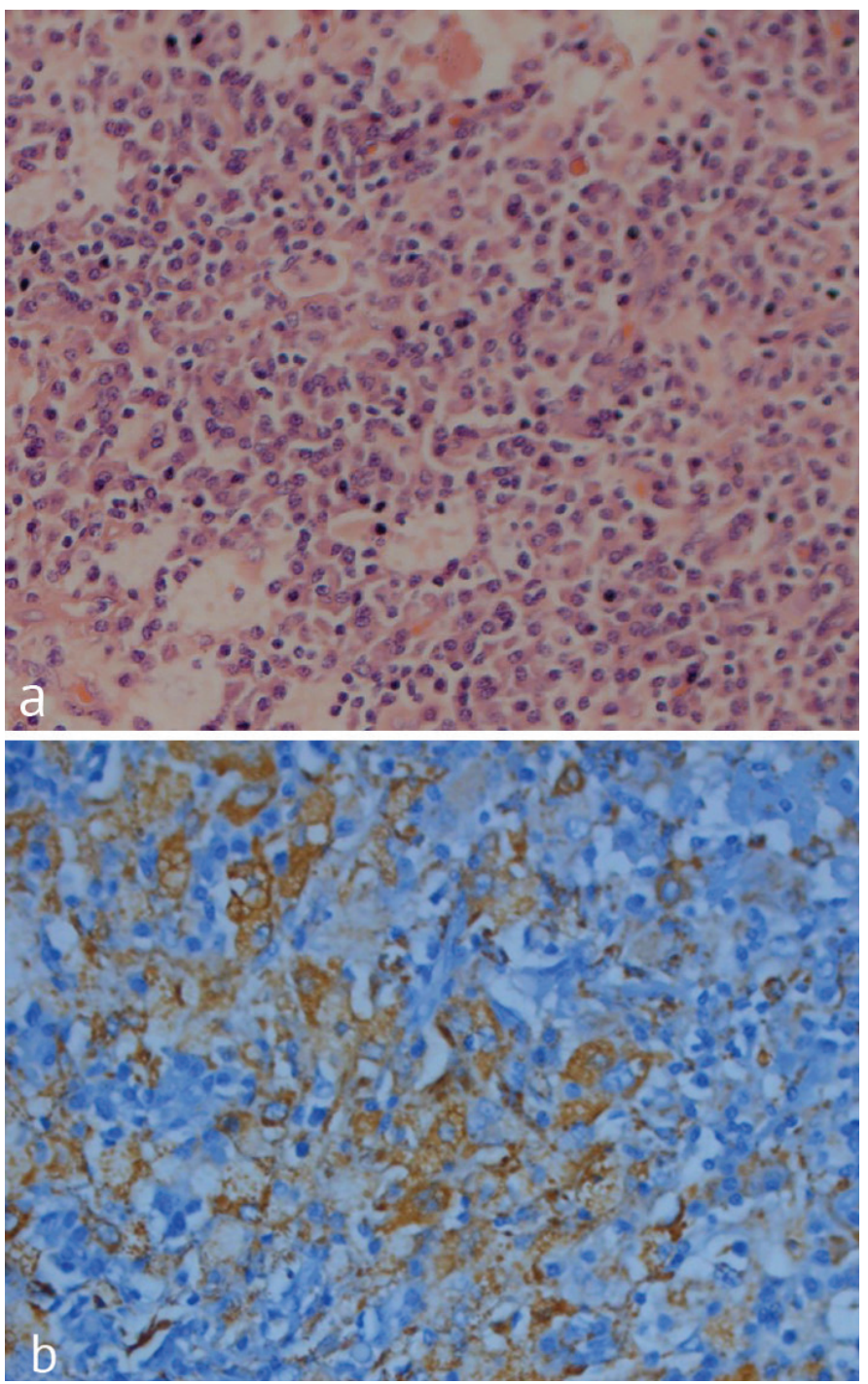

FIG. 3. a, b. (a) Hematoxylin and eosin staining of the specimen which revealed diffuse aggregats of histiocytoid cells with neutrophils, plasma cells and lymphocytes (HEx100). (b) Emperipolesis of lymphocytes in histiocytes with positivity for immunstain S-100 (x400).
Sinus histiocytosis with massive lymphadenopathy, known as RDD, is a rare, nonmalignant histiocytic proliferative disorder. Although the proliferation of the histiocytes is present in the pathogenesis, the etiology is unknown and classically it presents with bilateral, massive, painless cervical lymphadenopathy, but approximately $40 \%$ of cases have extranodal involvement. Extranodal RDD mostly involves the skin, nasal cavity and paranasal sinuses, orbita, upper respiratory tract, and bones $(1,2)$. Cardiac involvement is very rare and occurs in less than $0.1 \%$ of cases (3). The lesion defined in the heart and mediastinum had a signal intensity similar to what was seen in Daruwalla et al. (4) case. Although the prognosis for RDD is usually good, fatal consequences had to be take into account with the involvement of vital organs such as the heart and mediastinum. Therefore, multidisciplinary researches should be conducted thoroughly.

Conflict of Interest: No conflict of interest was declared by the authors.

\section{REFERENCES}

1. Buchino JJ, Byrd RP, Kmetz DR. Disseminated sinus histiocytosis with massive lymphadenopathy: its pathologic aspects. Arch Pathol Lab Med 1982;106:13-6.

2. Ercan İ, Şentürk T, Başak T, Çakır BÖ, Civelek Ş, Turgut S. Rosai-Dorfman Disease: Case presentation. KBB-Forum. 2005;4:101-1032.

3. Sendrasoa FA, Ranaivo IM, Raharolahy O, Andrianarison M, Razanakoto $\mathrm{NH}$, Ramarozatovo LS,et al. Rosai-Dorfman Disease Involving Multiple Organs: An Unusual Case with Poor Prognosis. Case Rep Med 2016;2016:3920516.

4. Daruwalla VJ, Parekh K, Tahir H, Collins JD, Carr J. Extranodal Rosai-Dorfman Disease Involving the Left Atrium: Cardiac MRI, CT, and PET Scan Findings. Case Rep Radiol 2015;2015:753160. 